\title{
Anesthetic management of an infant with Pierre Robin sequence undergoing tracheostomy using an i-gel ${ }^{\mathrm{TM}}$
}

\author{
Keisuke Omiya * ${ }^{*}$ and Takashi Matsukawa
}

Keywords: Pierre Robin sequence, I-gel $\mathrm{I}^{\mathrm{T}}$, Tracheostomy, Infant

To the Editor:

Pierre Robin sequence (PRS) is defined as the clinical triad of micrognathia, glossoptosis, and airway obstruction. Proper airway management is necessary during infancy because children with PRS frequently experience respiratory failure in early life [1]. There are some reports that a laryngeal mask airway (LMA) and the Air- $Q^{\circ}$ (Mercury Medical, Clearwater, FL, USA) are effective for airway management in patients with PRS [2, 3]. There are also some reports that the $\mathrm{i}$-gel ${ }^{\mathrm{Tm}}$ (Intersurgical, Wokingham, UK) is more effective than an LMA because inserting an $\mathrm{i}$-gel ${ }^{\mathrm{m}}$ takes less time than inserting an LMA [4, 5]; furthermore, the $\mathrm{i}^{- \text {gel }^{\mathrm{Tm}}}$ has greater leak pressure than the LMA [5]. However, there are no case reports regarding tracheostomy of infants with PRS, especially young infants approximately 1 month old, using an i-gel ${ }^{\mathrm{mx}}$. Therefore, we evaluated the use of the i-gel ${ }^{\mathrm{Tm}}$ as a supraglottic airway device (SGA) during this procedure.

The patient was a 46-day-old boy with a height of 49 $\mathrm{cm}$ and a weight of $2.6 \mathrm{~kg}$. He was born at 37 weeks and weighed $1970 \mathrm{~g}$. He was diagnosed with PRS because he had micrognathia and a cleft palate at birth. The patient's pharyngeal view was categorized as Mallampati class IV. It was possible to fit a mask to his face. A tracheostomy was scheduled because of worsening airway obstruction.

Preanesthetic medication was not administered. An intravenous catheter was placed before the patient entered the operating room. Electrocardiography, percutaneous oxygen saturation, and noninvasive arterial blood pressure were monitored after the patient entered

* Correspondence: k.omiya0303@gmail.com

Department of Anesthesiology, Faculty of Medicine, University of Yamanashi, 1110 Shimokato Chuo-shi, Yamanashi 409-3898, Japan the operating room. We induced general anesthesia after preoxygenating the patient with $5 \mathrm{~L} / \mathrm{min}$ oxygen for 3 min. First, we administered $0.06 \mathrm{mg}$ intravenous injection (IV) atropine, $6 \mu \mathrm{g}$ IV fentanyl, and $6 \mathrm{mg}$ IV propofol. We were able to provide ventilation via a mask; subsequently, we administered $3 \mathrm{mg}$ of IV rocuronium. We then attempted to intubate the patient with an uncuffed endotracheal tube ( $3.0 \mathrm{~mm}$ internal diameter) using an AirWay Scope ${ }^{\mathrm{mm}}$ (AWS $^{\mathrm{m}}$, Pentax, Humburg, DE). However, we could not visualize the vocal cords (Cormach-Lehane grade 4). We knew that attempts at tracheal intubation frequently lead to laryngeal edema and the inability to provide ventilation. Therefore, we inserted an i-gel ${ }^{\mathrm{Tm}}$ (size1). We were able to provide ventilation via the $\mathrm{i}-\mathrm{gel}^{\mathrm{mm}}$, and thought that it would be possible to perform a tracheostomy if we could provide ventilation via the $\mathrm{i}-$ gel $^{\mathrm{m}}{ }^{\mathrm{m}}$ using rocuronium to open the glottis. Anesthesia was maintained with a gas mixture of oxygen, air (fraction of inspired oxygen $\left.\left(\mathrm{FIO}_{2}\right), 0.3-0.7\right)$ and sevoflurane (1-1.5\%), and remifentanil $(0.1-0.5 \mu \mathrm{g} /$ $\mathrm{kg} / \mathrm{min}$ ) and rocuronium (single injection of $1.5 \mathrm{mg}$ ) were administered. We were able to perform a tracheostomy and surgery without complications.

We successfully used an i-gel ${ }^{\mathrm{m}}$ for anesthetic management of an infant with PRS who was undergoing tracheostomy.

\section{Abbreviations}

AWS ${ }^{\mathrm{TM}}$ : AirWay Scope ${ }^{\mathrm{TM}}$; IV: Intravenous injection; LMA: Laryngeal mask airway; PRS: Pierre Robin sequence; SGA: Supraglottic airway device

\section{Acknowledgments}

I would like to thank American Journal Experts ${ }^{\oplus}$ for the English language editing.

Funding

No funding was received. 


\section{Availability of data and materials}

Data sharing not applicable to this article as no data sets were generated or analyzed during the current study.

\section{Authors' contributions}

$\mathrm{KO}$ collected the patient data and drafted the manuscript. TM revised the manuscript. Both authors read and approved the final manuscript.

\section{Authors' information}

The corresponding author's secondary institution is Shizuoka Children's

Hospital, Japan.

\section{Ethics approval and consent to participate}

Written informed consent was obtained from the parents of this patient for publication of this case report and any accompanying images.

\section{Consent for publication}

Written informed consent for publication was obtained from the parents of this patient.

\section{Competing interests}

The authors declare that they have no competing interests.

\section{Publisher's Note}

Springer Nature remains neutral with regard to jurisdictional claims in published maps and institutional affiliations.

Received: 4 January 2019 Accepted: 14 February 2019

Published online: 19 February 2019

\section{References}

1. Van den Elzn AP, Semmekrot BA, Bongers EM, Huygen PL, Marres HA. Diagnosis and treatment of the Pierre Robin sequence: results of a retrospective clinical study and review of the literature. Eur J Pediatr. 2001, 160:47-53.

2. Templeton TW, Bryan YE. A two-stage approach to induction and intubation of two infants with Pierre Robin sequence using a LMA Classic ${ }^{\mathrm{TM}}$ and Air-Q ${ }^{\ominus}$ : two cases report. Korean J Anesthesiol. 2016;69:390-4.

3. Iwai H, Kanai R, Takasu Y, Hirabayashi Y, Seo N. Successful tracheal intubation using the pediatric Airtraq optical laryngoscope in a pediatric patient with Robin sequence. Masui. 2011;60:189-91.

4. Lee JR, Kim MS, Kim JT, Byon HJ, Park YH, Hs K, et al. A randomised trial comparing the 1 -ge ${ }^{T M}$ with the LMA Classic ${ }^{\text {TM }}$ in children. Anaesthesia. 2012; 67:606-11.

5. Lee YC, Yoon KS, Park SY, Choi SR, Chung CJ. A comparison of i-gel ${ }^{\mathrm{TM}}$ and Laryngeal Mask Airway Supreme ${ }^{\mathrm{TM}}$ during general anesthesia in infants. Korean J Anesthesiol. 2018;71:37-42.

\section{Submit your manuscript to a SpringerOpen ${ }^{\circ}$ journal and benefit from:}

- Convenient online submission

- Rigorous peer review

- Open access: articles freely available online

High visibility within the field

- Retaining the copyright to your article 